\title{
Parametric Investigation on Single Cylinder Spark Ignition Engine Fueled Methanol Blends; Water-Based Micro Emulsions and Conventional Gasoline
}

\author{
Ufaith Qadiri $^{*}$, Amjad Ali Pasha ${ }^{2}$, Mustafa Mutiur Rahman ${ }^{3}$, Mohammed Abdul Raheem ${ }^{4}$, Abdul Gani Abdul \\ Jameel $^{5}$, Subramania Nadaraja Pillai ${ }^{6}$ \\ ${ }^{1}$ Department of Mechanical Engineering, Malla Reddy Engineering College, Telangana, Medchal 500100, India \\ ${ }^{2}$ Department of Aerospace Engineering, King Abdulaziz University, Jeddah 21589, Saudi Arabia \\ ${ }^{3}$ Department of Mechanical and Mechatronics Engineering, University of Waterloo, ON, N2L 3G1, Canada \\ ${ }^{4}$ Independent Researcher, Telangana, Hyderabad 500053, India \\ ${ }^{5}$ Department of Chemical Engineering, King Fahd University of Petroleum and Minerals, Dhahran 31261, Saudi Arabia \\ ${ }^{6}$ Turbulence and Flow Control Lab, School of Mechanical Engineering, SASTRA Deemed University, Tamil Nadu 613401, \\ India
}

Corresponding Author Email: ufaithqadiri@mrec.ac.in

https://doi.org/10.18280/ijht.390327

Received: 20 January 2021

Accepted: 24 March 2021

\section{Keywords:}

AVL boost, alternative fuel, combustion, performance, emissions

\begin{abstract}
In this contribution, the investigation conducted on alternative fuels includes methanol $20 \%$ blended with gasoline $80 \%$ and emulsion-based fuel with the composition of gasoline $80 \%$, ethanol $15 \%$, and $\mathrm{H}_{2} \mathrm{O} 5 \%$ are compared with $100 \%$ conventional gasoline fuel. These fueled single-cylinders spark ignition engine is studied for checking their performance and emission characteristics as per future emission norms. This work is performed on One-dimensional AVL Boost Simulation Software. The simulations predicted the performance and emission characteristics were far lesser than conventional $100 \%$ gasoline. These fuels meet the strict emission regulations of Euro VII. The main purpose of this investigation is to use alternative fuels to improve the performance and emission characteristics of the single- cylinder spark ignition engine and reduce the consumption of fossil fuel reserves. This investigation led to the conclusion that by using methanol $20 \%$ in $80 \%$ gasoline and micro-emulsion, fuel improves the power, BSFC (brake specific fuel consumption), thermal efficiency and combustion properties of the single-cylinder spark-ignition engine. The $\mathrm{CO}, \mathrm{HC}$ and NOx emissions were also reduced for alternative fuel than $100 \%$ gasoline fuel. The novel water-based emulsion fuel showed the lowest value of NOx emissions as compared to blended $20 \%$ methanol with $80 \%$ gasoline and $100 \%$ gasoline fuel.
\end{abstract}

\section{INTRODUCTION}

The world is now consuming its petroleum resources faster than the rate at which they were formed by a natural process over the last several million years. This geological legacy, which is non-renewable, cannot be expected to last for a long time. The geological survey reveals that fossil fuel reserves will last only for a few decades. India, which is considerably dependent upon the import of petroleum to cater to its need for automobiles and other industrial applications, is spending considerable foreign exchange earnings. With rapid industrialization and the demand for vehicles day by day, the need for conventional fuels is increasing at a rapid rate. With this increase in demand for fuel, there are greater chances that the fossil fuel reserves will diminish, and the prices of petroleum fuel will touch the sky, which can affect our economy. The petroleum resources depletion rate could be controlled by exploring the other possible alternative fuels. Internal combustion engines are one of the major consumers of fossil fuels, and hence it needs urgent attention to the search for alternative fuels [1]. The alternative fuel that is used for an internal combustion engine should be available cheaply and easily from renewable resources. Its operation should be trouble-free by having low contaminating emissions under allowable limits. It should work in a dual-fuel mode without modifying the existing engine so that in case of nonavailability of alternative fuel, it can be easily switched over to the conventional fuel operation. Some important possible alternative fuels for internal combustion engines are methanol, ethanol, biogas, and hydrogen. Although methanol and ethanol could be used for both automotive and stationary applications, their production in India is not substantial to make them readily available for engine applications. Further, alcohols need separate carburetors or injectors to feed them into the combustion chamber. So presently, researchers are only using ethanol and methanol in some percentage blended with gasoline. Among other alternative fuels for internal combustion engines, biofuel seems very efficient and promising substitutes and rendering safe operation. This could also be produced from any type of organic waste such as cattle dung, animal wastes, organic agriculture wastes, organic wastes from industries. Production of biogas does not require any chemical plants. It is simply produced by bacterial action of organic waste, which is natural and does not require any moving machinery. This reduces maintenance, wear and tear, and requires only nominal human assistance to charge the plant. Further, this gives a neat appearance and does not give any objectionable odors. The utilization of biogas seems to be 
a good proposition for an agriculturally based country like India, where organic waste is abundantly available.

Biogas is rich in methane content, which is a combustible gas. The methane content generally varies between 55 and 70 percent, depending upon the freed material. It has 27 to 45 percent of $\mathrm{CO}_{2}, \mathrm{NOx}$, water vapor, and hydrogen sulfide and has a calorific value ranging between $19000 \mathrm{~kJ} / \mathrm{kg}$ and $24 \mathrm{~kJ} / \mathrm{kg}$ [2]. Yucesu et al. [3] checked the effect of varying compression ratios on the performance and emission characteristics at full load, stoichiometric air/fuel ratio, and at minimum advance timings for getting the best torque on a single-cylinder four-stroke engine [3]. They claimed that engine torque increased with an increase in compression ratio. Liu et al. [4] conducted research, and they claimed that engine power and torque shows decreasing trend when increasing the methanol in conventional gasoline engine under open throttle conditions. Also, they claimed by increasing the spark ignition timing at wide-open throttle (WOT) conditions increases the power and torque at the start. Koc et al. [5] studied the effects of gasoline and gasoline-ethanol blends on the performance and emission characteristics of single-cylinder spark-ignition engines at varying compression ratios. They have changed the engine speed from 1500 to $5000 \mathrm{rpm}$ at WOT conditions. The results they claimed are improvement in engine performance and ethanol/gasoline blends allow higher compression ratios without knocking.

The one-dimensional-based single-cylinder constant Speed spark-ignition engine model is used for simulation in AVL Boost software, as shown in Figure 1. This model was developed in software by connecting various pipes, and parts of the engine. After developing the model, each engine part was given initial and final conditions values and its geometrical properties were given as per the geometry of the single-cylinder SI engine present in the lab. The geometrical properties and engine specifications are given in Table 1.

Table 1. Geometrical properties and engine specification

\begin{tabular}{cc}
\hline Criteria & Description \\
\hline Make & Briggs \& Stratton \\
Type & Air-cooled 4 Stroke \\
Compression Ratio & 9 \\
Bore \& Stroke & $65.09 \mathrm{~mm} \times 61.91 \mathrm{~mm}$ \\
Cooling System & Air-cooled \\
Maximum HP & 6.5 \\
Displacement & $206 \mathrm{cc}$ \\
Ignition System & Magnetron Electronic \\
\hline
\end{tabular}

\subsection{Simulation setup}

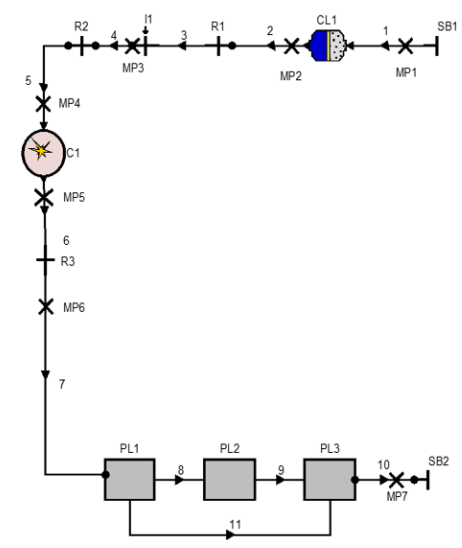

Figure 1. The plot of the One-dimensional single-cylinder SI engine model

\subsection{Methodology}

In this research work, the blended fuel used is gasoline $85 \%$ and ethanol $15 \%, \mathrm{H}_{2} \mathrm{O}$-ethanol based micro-emulsion was also prepared by blending the two fuels, and water was added in emulsion fuel. The composition used for this fuel is gasoline $85 \%$, ethanol $10 \%$, and $\mathrm{H}_{2} \mathrm{O} 5 \%$. Finally, the two fuels were studied and compared with conventional gasoline. This work concludes that all the fuels show an almost equal value of performance parameters and emissions. However, conventional $100 \%$ was slightly more in power in comparison with ethanol-blended fuels and water-ethanol-based microemulsions. This is because conventional fuel has more calorific value than other fuels, so power shows a slight increase in the curve. Also, emissions were far lesser for ethanol and emulsion-based fuel. The possible reason for this decrease is that number of carbon atoms in methanol is only one. Therefore, emissions are far lesser than ethanol blend and water-based emulsion as a fuel.

\section{MATHEMATICAL MODEL}

The utility of an alternative fuel could be best judged by conducting experiments in a laboratory, undoubtedly is beneficial in optimizing an engine for a specific application. In case it is necessary to do it over a wide range of design and operational parametric studies, it involves extensive fabrication and expensive engine testing. The internal combustion engine is a complex mechanical device, which embodies the principles of thermodynamics, chemical kinetics, heat transfer, transport phenomena and fluid mechanics in concert, providing complex dynamic interaction and interdependence among variables in the system $[6,7]$. It is very difficult to understand complex reactions and have a better insight into the behavior of such systems with mere laboratory experiments.

One of the tools that have been brought to the fore in meeting this challenge is the mathematical model for internal combustion engines. With the advent of high-speed digital computers, numerical simulation of internal combustion engine processes has played a significant role.

Before the engine can be run on a test rig after modification, the simulation model is made in AVL Boost Software before fabrication and the entire range of performance and emission characteristics could be determined. The accuracy of the obtained results depends on the details included in the model. Comprehensive models often require extensive computer time. Hence, a choice must be made between accuracy and computer time. Computer models predict the behavior of the engine satisfactorily. This would enable the designers to alter the design and operational parameters easily on the computer so that the behavior of the entire engine system could be assessed over a wide range of operating conditions. Such a procedure would undoubtedly lead to easy optimization and less fabrication work. This would not only narrow down the range of experimentation but also reduce the time and cost of engine testing [8].

\section{COMBUSTION MODELS}

The combustion models for spark ignition engines can be classified into three categories.

1. Specified pattern to represent the apparent rate of heat 
release (ROHR)

2. Single-zone models.

3. Multizone models.

The release was generally taken with the assumption that the heat release occurred for 40-50 degrees of crank angle. Although this model may not simulate the actual combustion process very accurately, it satisfactorily predicts the performance. To represent the tail portion of heat release, sometimes a modified triangular pattern of heat release is adapted with the tail portion extending up to the point where the exhaust valve opens. Applying the first law of thermodynamics and equation of state Krieger [9] analyzed the cylinder pressure diagrams to determine the rate of heat release. The heat release diagram so obtained was assumed as input data to the cycle calculations.

\subsection{Single zone combustion models}

In a single-zone combustion model, the mixture is assumed with composition uniform with no pressure or temperature gradients. The assumption is more representative of the conditions of a high-speed engine, where the cylinder contents are likely to mix uniformly due to swirl.

Ramos developed a relation between fuel injection and rate of heat release for direct injection engines. The fuel injection process may be divided into several short steps. The fuelinjected during one such step is prepared and then burnt in a particular way, following a simple mathematical formula [10].

\subsection{Multi-zone models}

Although the single-zone models could satisfactorily predict the performance, there are inadequacies due to the neglect of temperature and composition gradients. Similarly, it was not possible to study the effect of factors like nozzle orifice diameter, etc. On the rate of air entrainment and utilization. Other limitations regarding the accurate prediction of exhaust emissions, where accurate history of pressure, temperature and oxygen availability is required in each zone of the combustion chamber. Consequently, several two-zone models and multi-zone models have been developed [11].

Two-zone models are relatively simple, where it is assumed at any time during the combustion process, the cylinder consists of a burning zone and an unburnt zone. The burning zone consists of fuel, products of combustion and air, whilst the unburnt zone comprises surrounding air.

In multi-zone models, the fuel spray is divided into several zones. The preparation and burning rates were continuously monitored for each zone. At any instant, the heat release is calculated by summing up the heat release rate in each zone.

The combustion model considered in this study is based on 2 zones, which specifies the rate of heat release by considering the burned and unburned mass fractions. Thus, the calculation of the thermodynamic state of the cylinder is based on the balance of energy as given below:

$$
\begin{gathered}
\frac{d m_{b} u_{b}}{d \alpha}=-p_{c} \frac{d V_{b}}{d \alpha}+\frac{d Q_{F}}{d \alpha}-\sum \frac{d Q_{W b}}{d \alpha}+h_{u} \frac{d m_{b}}{d \alpha} \\
-h_{B B, b} \frac{d m_{B B, b}}{d \alpha} \\
\frac{d m_{u} u_{u}}{d \alpha}=-p_{c} \frac{d V_{u}}{d \alpha}-\sum \frac{d Q_{W u}}{d \alpha}-h_{u} \frac{d m_{b}}{d \alpha} \\
-h_{B B, u} \frac{d m_{B B, u}}{d \alpha}
\end{gathered}
$$

where:

index $\mathrm{b}$ : burned zone index;

index $\mathrm{u}$ : unburned zone;

$\frac{d(m \cdot u)}{d \alpha} \quad$ : change on the internal energy in the cylinder;

$-p_{c} \frac{d V}{d \alpha}:$ piston work;

$\frac{d Q_{F}}{d \alpha} \quad$ : fuel heat input;

$\sum \frac{d Q_{W}}{d \alpha} \quad$ : wall heat losses;

$h_{B B} \frac{d m_{B B}}{d \alpha}$ : enthalpy flow due to blow-by;

$h_{u} \frac{d m_{b}}{d \alpha}-h_{B B, u}$ : enthalpy flow from the unburned to the burned zone due to the conversion of a fresh charge to the combustion products [12].

$$
\begin{gathered}
\frac{d V_{b}}{d \alpha}+\frac{d V_{u}}{d \alpha}=\frac{d V}{d \alpha} \\
V_{\mathrm{b}}+V_{\mathrm{u}}=V
\end{gathered}
$$

\section{RESULTS AND DISCUSSION}

In Figure 2, the plot shows the variation of power with varying percentage load on the engine. The plot gives a clear view of power for all types of fuels. The investigation is performed with three types of fuels in which ethanol and methanol are used as alternative fuels for possible improvement in performance and emission characteristics. As the load on the engine increases, the power also shows the increasing trend for all types of fuels. However, gasoline is slightly more in power as compared to blended fuels and water-based emulsion fuels. The reason for this increase in power is that gasoline has more calorific value than methanol and ethanol fuel [13].

In Figure 3, the variation of torque has been defined with an increase in load percentage. As the load increases, the torque on the engine also increases for all the fuels. The plot gives a clear view of how torque increases with increasing load. This gives the idea that the more the torque more is the power produced by the engine as torque is the ability of the engine to produce power. Again, the torque is slightly more for gasoline $100 \%$ fuel due to the more heating value. Nevertheless, methanol and ethanol are also showing very good results in terms of torque produced as both can produce power and can run the engine when used as blended fuel [14].

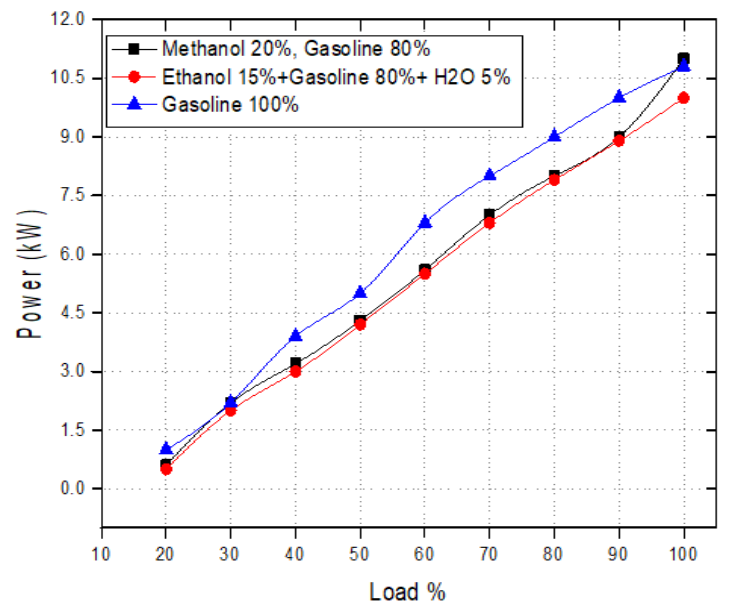

Figure 2. The variation of power of single-cylinder constant speed spark ignition engine under varying load \% conditions 


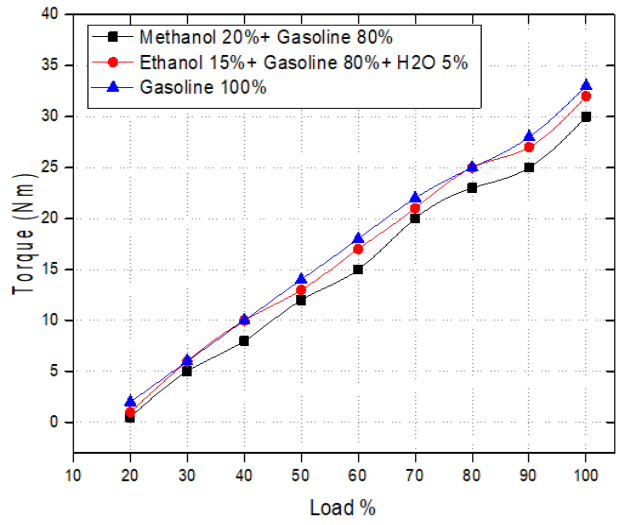

Figure 3. The variation of Torque on single-cylinder sparkignition engine under varying load

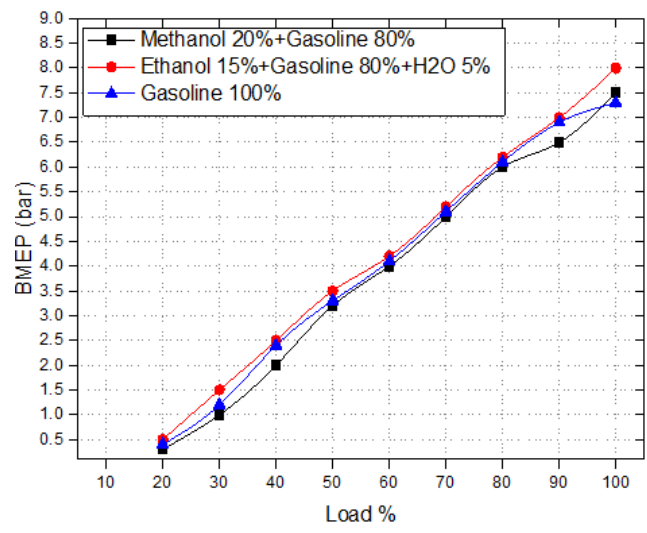

Figure 4. The variation of BMEP of single-cylinder constant speed spark ignition engine under varying load $\%$ conditions

In Figure 4, the variation of BMEP was checked with load percentage. As the plot shows an increasing trend for all the types of fuels. This plot gives the average pressure produced inside the engine. Besides, the engines can produce work. Since all the fuels show an equal type of trend so this suggests that all the fuels produce almost equal average pressure, which can be obtained in terms of work output at the crankshaft. Here it can be seen that ethanol-based emulsion showed slightly higher BMEP than the other two types of fuels. This is because by addition of ethanol in gasoline increases the power and average pressure inside the combustion chamber by increasing its calorific value and thereby increases average pressure and work output [15].

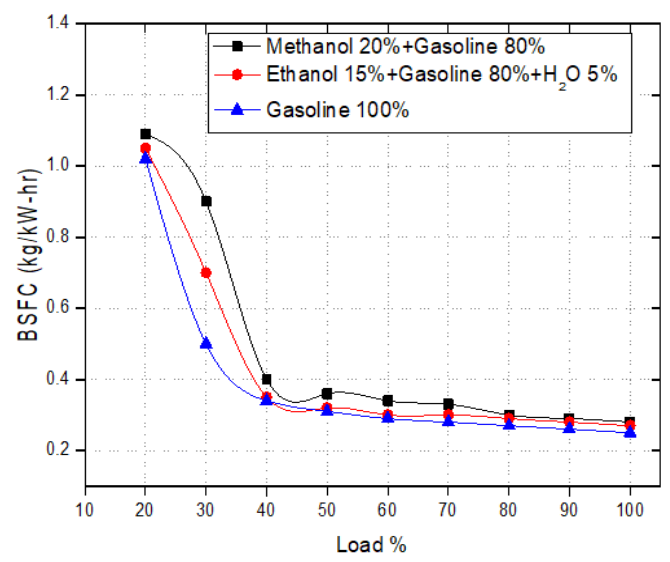

Figure 5. The variation of BSFC of single-cylinder constant speed spark ignition engine under varying load

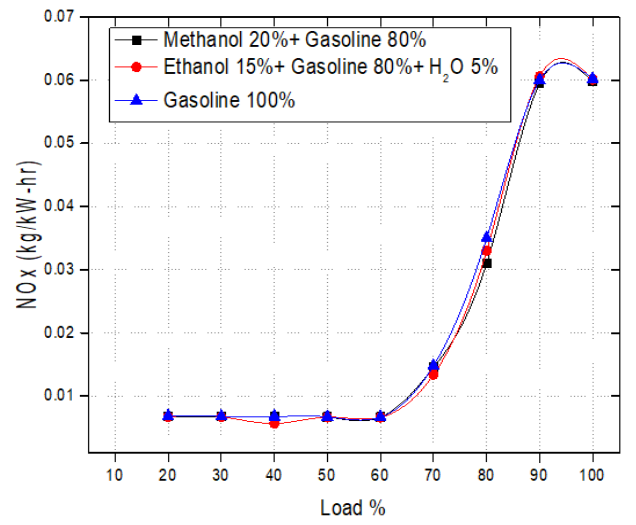

Figure 6. The variation of NOx emissions of single-cylinder constant speed spark ignition engine under varying load $\%$ conditions

In Figure 5, the BSFC can be seen showing a decreasing trend for all the fuel inputs. Since the start of the combustion engine needs more power and more fuel for proper combustion of fuel and the mixture is rich. Therefore, the consumption of fuel increases at the starting load conditions. Also, when the load on the engine increases, the mixture turns more towards the leaner side, which results in a decrease in fuel consumption at increasing loads for all the types of fuels. The highest BSFC value is for methanol blended fuel because it has the lowest calorific value as compared to ethanol and gasoline. Therefore, this results in slightly more consumption of fuel when using methanol $20 \%$ and ethanol $15 \%$ as blended fuels in the engine [16].

In Figure 6, the variation of NOx with percentage load has been defined. This plot shows that by increasing load on the engine, the NOx emissions also increase. The curve is almost the same for all types of fuels. As NOx is formed when the temperature inside the combustion chamber increases resulting in the chemical reaction of nitrogen present in the air, and oxygen present in the fuel as well as in the atmosphere at high temperature forms the NOx emissions. The slightly more NOx emission is for gasoline $100 \%$. This is because conventional fuel at increasing load increases the temperature inside the combustion chamber, which slightly increases the NOx emissions. ethanol has in build oxygen atom in its chemical structure and the addition of $\mathrm{H}_{2} \mathrm{O}$ increases the oxygen concentration inside the combustion chamber, which results in the complete combustion of fuel and thereby reducing the temperature and decreases the NOx emissions [17].

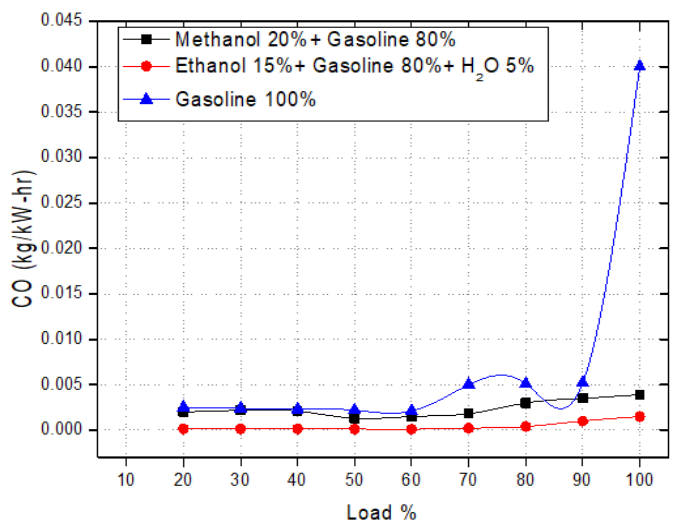

Figure 7. The variation of $\mathrm{CO}$ emissions of single-cylinder constant speed spark ignition engine under varying load 


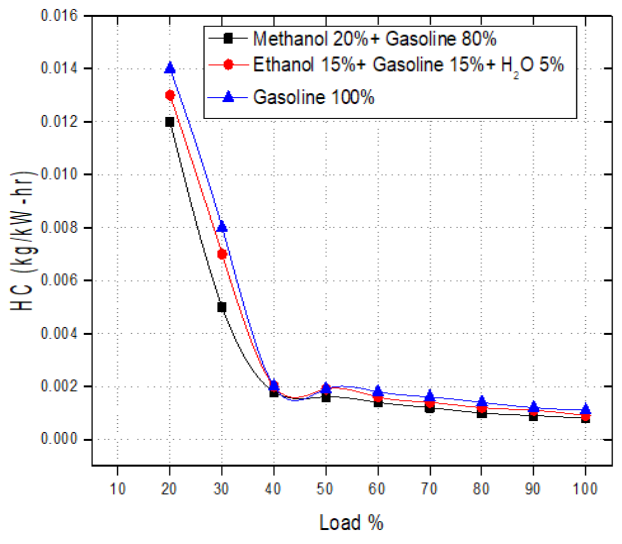

Figure 8. The variation of $\mathrm{HC}$ emissions of single-cylinder constant speed spark ignition engine under varying load

In Figure 7, the $\mathrm{CO}$ emissions show very fewer emissions at the lower loads on the engine. At lower loads, the combustion of fuel burns very smoothly and fuel gets sufficient time for its complete combustion and the $\mathrm{CO}$ emissions decrease. This is because methanol and ethanol contain oxygen atoms in their molecular structure, which results in their complete combustion when used in a blended form in the engine. As the load on the engine increases, the gasoline $100 \%$ does not get sufficient time for complete oxidation of fuel and incomplete combustion takes place, so the gasoline $100 \%$ showed an increase in $\mathrm{CO}$ emissions at higher loads [18].

In Figure 8, the variation of $\mathrm{HC}$ emissions was compared for three types of fuels. The HC emissions are formed due to fuel goes inside the crevices and due to incomplete combustion of fuel at the starting of the engine at lower loads. With an increase in load, the fuel-air mixture turns more towards the leaner side and results in the complete combustion of fuel. This results in a lower value of $\mathrm{HC}$ emissions at higher loads. Almost all the fuels are efficient in terms of CO emissions, but methanol $20 \%$ with gasoline $80 \%$ proves more efficient at lower loads which shows slightly fewer $\mathrm{HC}$ emissions as compared to ethanol and gasoline fuels [19].

In Figure 9, the plot of pressure can be seen with varying crank angles. The combustion pressure showed almost equal pressure for all types of fuels. This can be seen on the pressure plot that peak pressure is around 35 bar with an increase in crank angle. The slightly lower value is for ethanol-based micro-emulsion fuel. The reason for this decrease in pressure is due to the presence of $\mathrm{H}_{2} \mathrm{O}$ molecule that lowers the temperature and pressure inside the combustion chamber [20, $21]$.

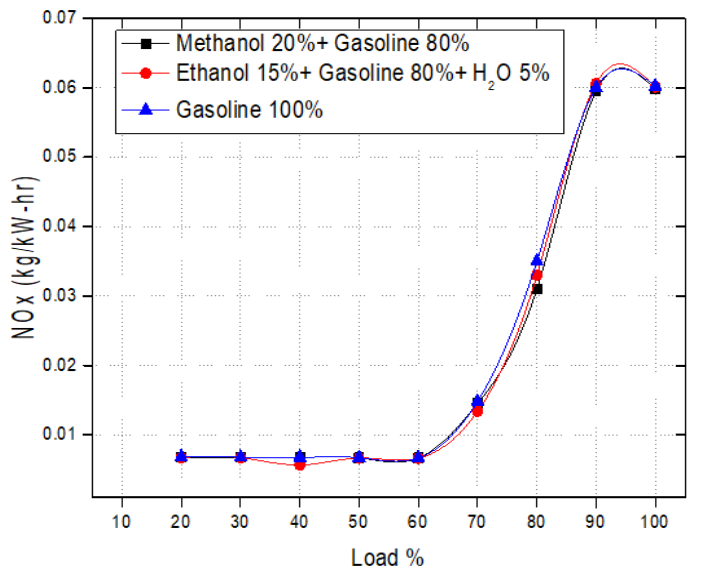

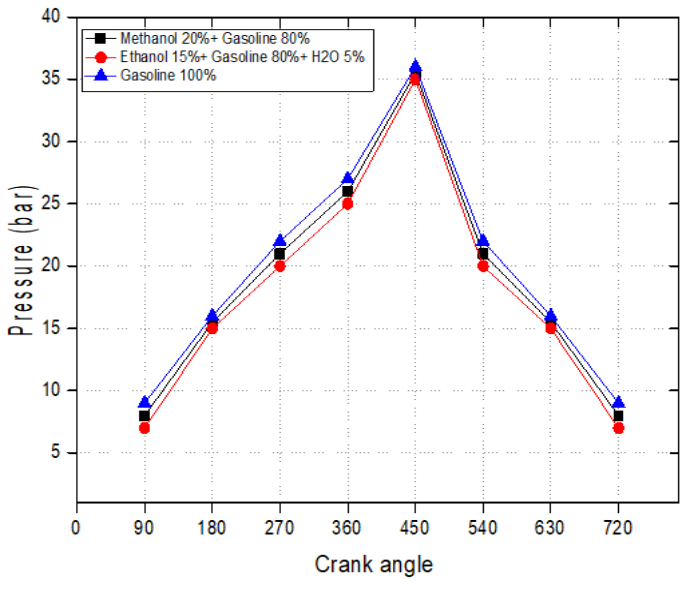

Figure 9. The variation of pressure of single-cylinder constant speed spark ignition engine under varying Crank angle conditions

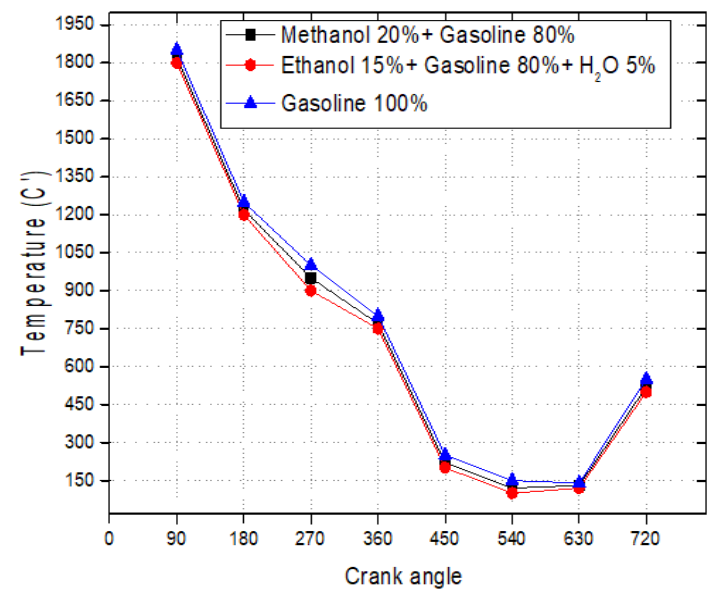

Figure 10. The variation of Temperature of single-cylinder constant speed spark ignition engine under varying Crank angle conditions

In Figure 10, the variation of temperature can be seen at varying crank angles. The temperature of the engine is highest at lower loads for all types of fuels. This is because at lower loads, the mixture is rich and the fuel supply increases, which results in the increase of its temperature and decreases with an increase in load when the mixture turns more towards the leaner side [21, 22].

\section{CONCLUSION}

This investigation was performed on AVL Boost Simulation Software for predicting the performance and emission characteristics of the single-cylinder spark-ignition engine using two types of blended fuels, namely methanol $20 \%$ in gasoline $80 \%$ and ethanol- $\mathrm{H}_{2} \mathrm{O}$ based emulsion fuel and were compared with $100 \%$ conventional gasoline fuel. The investigation leads to the following conclusion that the methanol $20 \%$ in gasoline $80 \%$ proves to be efficient fuel in terms of performance and emission characteristics. The power showed more increase than ethanol- $\mathrm{H}_{2} \mathrm{O}$-based microemulsion fuel. ethanol- $\mathrm{H}_{2} \mathrm{O}$-based micro-emulsion fuel also proved efficient fuel as the emissions showed very less value as compared to $100 \%$ conventional gasoline fuel. Both methanol and ethanol addition reduce the NOx emissions more 
than $100 \%$ conventional gasoline fuel. As the addition of oxygen atom and $\mathrm{H}_{2} \mathrm{O}$ molecule reduces the combustion temperature by complete oxidation of fuel. The $\mathrm{CO}$ and $\mathrm{HC}$ emissions were also lower than $100 \%$ conventional gasoline fuel and proved to be efficient fuel in terms of emission characteristics.

\section{ACKNOWLEDGEMENT}

We are thankful to AVL Austria that provided us the software AVL Boost for Engine Simulations. We are also thankful to the NIT Srinagar for providing the lab facility and Malla Reddy Engineering College for encouraging the research work.

\section{REFERENCES}

[1] Bhattacharyya, B.C. (1979). Design and economy of Gobar (bio) gas plant for rural use. Chem. Age (India), 30: 923-960.

[2] Kelebe, H.E., Olorunnisola, A. (2016). Biogas as an alternative energy source and a waste management strategy in Northern Ethiopia. Biofuels, 7(5): 479-487. https://doi.org/10.1080/17597269.2016.1163211

[3] Yücesu, H.S., Topgül, T., Cinar, C., Okur, M. (2006). Effect of ethanol-gasoline blends on engine performance and exhaust emissions in different compression ratios. Applied Thermal Engineering, 26(17-18): 2272-2278. https://doi.org/10.1016/j.applthermaleng.2006.03.006

[4] Liu, S., Clemente, E.R.C., Hu, T., Wei, Y. (2007). Study of spark ignition engine fueled with methanol/gasoline fuel blends. Applied Thermal Engineering, 27(11-12): 19041910 https://doi.org/10.1016/j.applthermaleng.2006.12.024

[5] Koç, M., Sekmen, Y., Topgül, T., Yücesu, H.S. (2009). The effects of ethanol-unleaded gasoline blends on engine performance and exhaust emissions in a sparkignition engine. Renewable Energy, 34(10): 2101-2106. https://doi.org/10.1016/j.renene.2009.01.018

[6] Qadiri, U., Wani, M.M. (2019). Computational investigation on single-cylinder spark ignition engine using gasoline-propane in dual fuel mode. International Journal of Heat and Technology, 37(2): 457-465. https://doi.org/10.18280/ijht.370211

[7] Qadiri, U., Wani, M.M. (2019). Experimental investigation on multi-cylinder SI engine fueled conventional gasoline, ethanol blends, and microemulsion as an alternative fuel. Mathematical Modelling of Engineering Problems, 6(1): 69-76. https://doi.org/10.18280/mmep.060109

[8] Karim, G.A., Wierzba, I. (1983). Comparative studies of methane and propane as fuels for spark ignition and compression ignition engines. SAE Transactions, 92: 676-688. https://doi.org/10.4271/831196

[9] Ramos, J.I. (1986). Comparisons between thermodynamic and one-dimensional combustion models of spark-ignition engines. Applied Mathematical Modelling, 10(6): 409-422. https://doi.org/10.1016/0307904X(86)90019-3

[10] Kumar, A., Khatri, D., Babu, M. (2008). Experimental investigations on the performance, combustion and emission characteristics of alcohol blended gasoline in a fuel injected spark ignition engine. SAE Technical Paper. https://doi.org/10.4271/2008-28-0068

[11] Prah, I., Trenc, F., Katrašnik, T. (2016). Innovative calibration method for system level simulation models of internal combustion engines. Energies, 9(9): 708. https://doi.org/10.3390/en9090708

[12] Yüksel, F., Yüksel, B. (2004). The use of ethanolgasoline blend as a fuel in an SI engine. Renewable Energy, 29(7): 11811191. https://doi.org/10.1016/j.renene.2003.11.012

[13] Agarwal, A.K. (2007). Biofuels (alcohols and biodiesel) applications as fuels for internal combustion engines. Progress in Energy and Combustion Science, 33(3): 233271. https://doi.org/10.1016/j.pecs.2006.08.003

[14] Nakata, K., Utsumi, S., Ota, A., Kawasaki, K., Kawai, T., Tsunooka, T. (2006). The effect of ethanol fuel on a spark ignition engine (No. 2006-01-3380). SAE Technical Paper.

[15] Al-Hasan, M. (2003). Effect of ethanol-unleaded gasoline blends on engine performance and exhaust emission. Energy Conversion and Management, 44(9): 1547-1561. https://doi.org/10.1016/S01968904(02)00166-8

[16] Turner, D., Xu, H., Cracknell, R.F., Natarajan, V., Chen, X. (2011). Combustion performance of bio-ethanol at various blend ratios in a gasoline direct injection engine. Fuel, 90(5): 1999-2006. https://doi.org/10.1016/j.fuel.2010.12.025

[17] Pearson, R.J., Turner, J.W., Bell, A., De Goede, S., Woolard, C., Davy, M.H. (2015). Iso-stoichiometric fuel blends characterization of physicochemical properties for mixtures of gasoline, ethanol, methanol and water. Proceedings of the Institution of Mechanical Engineers, Part D: Journal of automobile engineering, 229(1): 111139. https://doi.org/10.1177\%2F0954407014529424

[18] Waqas, M., Naser, N., Sarathy, M., Feijs, J., Morganti, K., Nyrenstedt, G., Johansson, B. (2017). Auto-ignition of iso-stoichiometric blends of gasoline-ethanolmethanol (GEM) in SI, HCCI and CI Combustion Modes (No. 2017-01-0726). SAE Technical Paper. https://doi.org/10.4271/2017-01-0726

[19] Turner, J.W.G., Pearson, R.J., Dekker, E., Iosefa, B., Johansson, K., Ac Bergström, K. (2013). Extending the role of alcohols as transport fuels using isostoichiometric ternary blends of gasoline, ethanol and methanol. Applied Energy, 102: 72-86. https://doi.org/10.1016/j.apenergy.2012.07.044

[20] Hsieh, W.D., Chen, R.H., Wu, T.L., Lin, T.H. (2002). Engine performance and pollutant emission of an SI engine using ethanol-gasoline blended fuels. Atmospheric Environ., 36(3): 410-410. https://doi.org/10.1016/S1352-2310(01)00508-8

[21] Naser, N., Jameel, A.G.A., Emwas, A.H., Singh, E., Chung, S.H., Sarathy, S.M. (2019). The influence of chemical composition on ignition delay times of gasoline fractions. Combustion and Flame, 209: 418-429. https://doi.org/10.1016/j.combustflame.2019.07.030

[22] Jameel, A.G.A., Oudenhoven, V.V., Emwas, A.H., Sarathy, S.M. (2018). Predicting octane number using nuclear magnetic resonance spectroscopy and artificial neural networks. Energy \& Fuels, 32(5): 6309-6329. https://doi.org/10.1021/acs.energyfuels.8b00556 